\title{
The Effect of Back Massage on Let Down Reflex among Mothers Who Had Undergone Cesarean Section
}

\author{
Bhagyashree Anil Jogdeo ${ }^{1}$, Dr. Nilima R. Bhore ${ }^{2}$ \\ ${ }^{1}$ Assistant Professor, Bharati Vidyapeeth College of Nursing Pune-43, India \\ PhD Nursing, BVDU College of Nursing, Pune, India \\ ${ }^{2}$ Professor, Bharati Vidyapeeth College of Nursing Sangli,India \\ PhD Nursing, BVDU College of Nursing,Sangli,India
}

\begin{abstract}
India alone .2 .7 million births occur in India out of which 1.7 million children die before one year of age and 1.08 million newborn die within one month of age. Most of the mortality occurs due to suboptimal breast feeding. Purpose: To study the effect of back massage on let down reflex among mothers who had undergone cesarean section. Objectives: to assess the effect of back massage on lactation among mothers who had undergone cesarean section. Material and methods: This was a quantitative quasi experimental pilot study with non equivalence control group design. Non probability Purposive sampling technique was used for the selection of sample. 10 samples for experimental group and 10 samples for control group from two different settings. During $10^{\text {th }}$ March 2015 to $25^{\text {th }}$ May 201 collected data. Tool was developed in two parts, first was demographic data of the mothers and second part includes semi structured questionnaire and observation checklist for let down reflex. Result: In experimental group Majority of the mothers had age 29-32 years of age, 50\% of the neonates were females and another half were males.70\% of them were receiving supplementary food to enhance lactation, all of the babies were breast feed 4-6 times per day. In control group $50 \%$ of them had age $29-32$ years of age, $20 \%$ of the neonates were females and $80 \%$ of them were males. $30 \%$ of them were receiving supplementary food to enhance lactation, $80 \%$ of the babies were breast feed 4-6 times per day. On pre assessment, in experimental and control group, $30 \%$ of the mothers had poor letdown reflex and another $70 \%$ of them had excellent letdown reflex. In experimental group average change in letdown reflex scores were 2.3, 2.3 and 2.6 on day1, day2 and day3. In control group average change in letdown reflex scores were $0,0.3$ and 0.3 . on day1, day 2 and day3. This shows that there is improvement in the letdown reflex of mothers in experimental group than control group. Conclusion: The study concluded that there was a significant increase in let down reflex in experimental group
\end{abstract}

Keywords: Effectiveness, back massage, letdown reflex, cesarean section

\section{Introduction}

Mother who has undergone cesarean section has a dual role in post operative care as well as maternal care. Breast feeding is more difficult after a caesarean section for many reasons maternal pain and fatigue, delayed access to baby, increased supplementary feeding, separation of mother and baby, blood loss causing anemia, effects of medication, stress.( Tiwari $R$, et al. 2005) ${ }^{1}$

\section{Review of Literature}

Maternal stress interfered with the release of oxytocin, the hormone responsible for milk ejection reflex. It also found that stressed newborns were more likely to be weak or too sleepy to latch and suckle effectively. (Khan M.2001) ${ }^{2}$ Studies show that the more the first breast feedings are delayed, the higher the rate of problems (Mathur, 1993). ${ }^{3}$

A randomized control study on primipara mothers of China to observe the differences between back massage and simple instruction and education to improve the lactation after delivery 56 samples $(28+28)$ of primipara were assessed experimental group treated with intervention and control group with simple instruction and education on breast feeding. The study concluded that parturient had sufficient milk in experimental group after treatment and the time start to lactate was earlier than control group. ${ }^{4}$

\section{Materials and Methods}

This study used the quantitative research approach. A quasi experimental study with non equivalence control group design was considered best sited to the study. This design was used since the study evaluated the effect of back massage (independent variable) on let down reflex among mothers who had undergone cesarean section.

Inclusion criteria - Mothers after 48 hours of caesarian section, undergone classical cesarean section or lower segment cesarean section. Mothers of New born babies with normal physiological characteristics, weight between 2.5-3.7 Kilogram,

Exclusion criteria - Mothers who are critically ill, receives medication for lactation, mothers with breast or nipple abnormalities, suffering from psychiatric disorder, with post dural puncture headache, delivered twins baby. The assessment of let down reflex was done immediately after back massage four times in a day for 3 days.

Description of the tool:

Section I: Demographic profile Section one was prepared to collect general information about the mother and her neonate. It is semi structured questionnaires about variables such as age and parity of mother, sex and birth weight of the neonate, Initiation of breast feeding after caesarian section, receiving any supplementary food to enhance lactation, 


\section{International Journal of Science and Research (IJSR) \\ ISSN (Online): 2319-7064 \\ Index Copernicus Value (2013): 6.14 | Impact Factor (2013): 4.438}

number of times neonate been breast feed per day, requirement of top feed, If yes how often.

Section II: Assessment of let down reflex. It includes semi structured questionnaire and observation check list.

Semi structured questionnaire regarding tingling sensation in breast and feeling of fullness of breast .These responses were scored with the provided guidelines i.e. Strong feelings scored as 3, Moderate feelings scored as 2, Mild feelings scored as 1 , the scores after each intervention were arbitrarily interpreted as follows 2 as a poor letdown reflex, 3-5 as a good letdown reflex, 6 as a excellent letdown reflex. Observation check list assessed after the back massage, mothers were observed for erectile nipple, release of breast milk, warm breast before breast feed to the neonate. After breast feeding breast was observed for softness. Yes response was scored as 1 and no response was scored as 0 . The scores were interpreted per intervention as follows: 0 to 1 as a poor letdown reflex, 2 to 3 as a good letdown reflex, and 4 as an excellent letdown reflex.

\section{Results and Analysis}

Section I: Demographic profile - In experimental group, $30 \%$ of the mothers were $25-28$ years of age and $70 \%$ of them had age $29-32$ years of age, $50 \%$ of the neonates were females and another $50 \%$ of them were males, $70 \%$ of the neonates had birth weight $2.5-3 \mathrm{~kg}$ and $30 \%$ of them had birth weight of 3-3.7 kg. 50\% of them initiated breast feeding within 4 hours after caesarian section and another half of them did it more than 4 hours after caesarian section,70\% of them were receiving supplementary food to enhance lactation, all of the babies were breast feed 4-6 times per day. In control group, $20 \%$ of the mothers were 25-28 years of age, $50 \%$ of them had age $29-32$ years of age and $30 \%$ of them had age above 32 years, $20 \%$ of the neonates were females and $80 \%$ of them were males, $20 \%$ of the neonates had birth weight of $2.5-3 \mathrm{~kg}$ and $80 \%$ of the neonates had birth weight 3-3.7 kg, 30\% of them initiated breast feeding within 4 hours of cesarean section

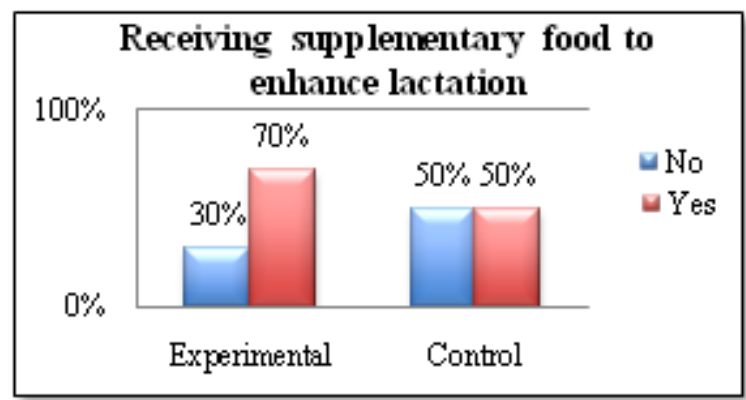

Figure 1: Receiving supplementary food to enhance lactation

$\mathbf{N}=\mathbf{2 0}$

Figure no 1 shows majorities received food to enhance lactation from experimental group and from control group $50 \%$ group received food to enhance lactation and other $50 \%$ does not received any supplimentory food to enhance lactation
Section II: Findings related to analysis of the data related to the pre assessment of let down reflex among mothers who had undergone cesarean section.

Table 1: Pre assessment of let down reflex based on semi structured questionnaire among mothers who had undergone caesarian section in both groups, $\mathbf{N}=\mathbf{2 0}$

\begin{tabular}{|c|c|c|c|c|}
\hline \multirow{2}{*}{$\begin{array}{c}\text { Letdown } \\
\text { reflex }\end{array}$} & \multicolumn{2}{|c|}{ Experimental Group } & \multicolumn{2}{c|}{ Control Group } \\
\cline { 2 - 5 } & Freq & $\%$ & Freq & $\%$ \\
\hline Poor & 5 & $50 \%$ & 5 & $50 \%$ \\
\hline Good & 5 & $50 \%$ & 5 & $50 \%$ \\
\hline Excellent & 0 & $0 \%$ & 0 & $0 \%$ \\
\hline
\end{tabular}

Table no. 1 shows half of the experimental group and control group had poor letdown reflex as well as another 50\% shows good letdown reflex in both the group.

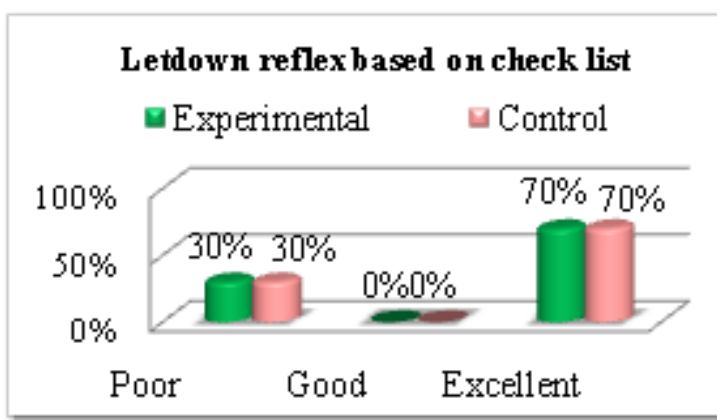

Figure no 1: To assess the Letdown Reflex score based on checklist among mothers who had undergone caesarian section in both groups, $\mathbf{N}=\mathbf{2 0}$

Bar diagram shows poor let down reflex was 30\% and excellent let down reflex was $70 \%$ in both the group.

Section III- Effectiveness of back massage on letdown reflex in experimental group

Table 2: Effectiveness of back massage on letdown reflex based on semi structured questionnaire in experimental

\begin{tabular}{|c|c|c|c|c|c|}
\hline Day & Mean & SD & T & df & p-value \\
\hline Day 0 & 3.1 & 0.7 & & & \\
\hline Day 1 & 5.4 & 0.6 & 9.095 & 9 & 0.000 \\
\hline Day 2 & 5.4 & 0.5 & 8.048 & 9 & 0.000 \\
\hline Day 3 & 5.7 & 0.3 & 10.049 & 9 & 0.000 \\
\hline
\end{tabular}

Researcher applied paired t-test for comparison of letdown reflex scores of mothers before and after back massage. Average letdown reflex score on pre assessment was 3.1 which increased to 5.4, 5.4 and 5.7. $\mathrm{t}$-values for this comparison with 9 degrees of freedom were 9.095. 8.048 And 10.049. Corresponding p-values were of the order of 0.000 , which are small (less than 0.05), the null hypothesis is rejected. Letdown reflex of the mothers improved significantly after back massage.

Table no 3: Effectiveness of back massage on letdown reflex based on observation check list in experimental group

\begin{tabular}{|c|c|c|c|c|c|}
\hline Day & Mean & SD & T & df & p-value \\
\hline Day 0 & 2.1 & 0.7 & & & \\
\hline Day 1 & 3.3 & 0.6 & 3.793 & 9 & 0.002 \\
\hline Day 2 & 3.9 & 0.1 & 8.933 & 9 & 0.000 \\
\hline Day 3 & 3.9 & 0.1 & 7.836 & 9 & 0.000 \\
\hline
\end{tabular}




\section{International Journal of Science and Research (IJSR) \\ ISSN (Online): 2319-7064}

Index Copernicus Value (2013): 6.14 | Impact Factor (2013): 4.438

Average letdown reflex score on pre assessment was 2.1 which increased to 3.3, 3.9 and 3.9. T-values for this comparison with 9 degrees of freedom were 3.7. 8.9and7.8. Corresponding p-values were $0.002,0.000$ and 0.000 , which are small (less than 0.05), the null hypothesis is rejected. Letdown reflex of the mothers improved significantly after back massage.

\section{Section IV: To compare the lactation among mothers who had undergone caesarian section in control group and experimental group}

Table 4: comparison of average change in letdown reflex scores based on semi structured questionnaire of experimental and control groups, $\mathbf{N}=\mathbf{2 0}$

\begin{tabular}{|c|c|c|c|c|c|c|c|}
\hline \multirow{2}{*}{ Day } & \multicolumn{2}{|c|}{ Exp Gr. } & \multicolumn{2}{c|}{ Control Gr. } & \multirow{2}{*}{$t$} & \multirow{2}{*}{$\begin{array}{c}p- \\
\text { value }\end{array}$} \\
\cline { 2 - 5 } & Mean & SD & Mean & SD & & & valunn \\
\hline Day 1 & 2.3 & 0.8 & 0.0 & 0.0 & 9.1 & 18 & 0.000 \\
\hline Day 2 & 2.3 & 0.9 & 0.3 & 1.0 & 4.7 & 18 & 0.000 \\
\hline Day 3 & 2.6 & 0.8 & 0.3 & 0.7 & 6.6 & 18 & 0.000 \\
\hline
\end{tabular}

Average changes in letdown reflex in experimental group were 2.3, 2.3 and 2.6 on day1, day2 and day3. Average change in letdown reflex score of control group were $0,0.3$ and 0.3. T-values for this comparison were 9.1, 4.7 and 6.6 with 18 degrees of freedom. Corresponding p-values were of the order of 0.000 which are small (less than 0.05), the null hypothesis is rejected. Back massage improved letdown reflex significantly in experimental group than control group.

Table 5 Comparison of average change in letdown reflex scores based on observational checklist of experimental and control groups, $\mathbf{N}=\mathbf{2 0}$

\begin{tabular}{|l|r|r|r|r|r|r|c|}
\hline \multirow{2}{*}{ Day } & \multicolumn{2}{|c|}{ Exp } & \multicolumn{2}{|c|}{ Control } & \multirow{2}{*}{ t } & \multirow{2}{*}{ df } & \multirow{2}{*}{ p-value } \\
\cline { 2 - 6 } & Mean & SD & Mean & SD & & & \\
\hline Day 1 & 1.1 & 1.0 & 0.03 & 0.4 & 3.4 & 18 & 0.002 \\
\hline Day 2 & 1.8 & 0.6 & 0.10 & 1.3 & 3.8 & 18 & 0.001 \\
\hline Day 3 & 1.8 & 0.7 & 0.05 & 1.3 & 3.8 & 18 & 0.001 \\
\hline
\end{tabular}

Average changes in letdown reflex in experimental group were $1.1,1.8$ and 1.8 on day1, day2 and day3. Average change in letdown reflex score of control group were 0.03 , 0.10 and 0.05 . T-values for this comparison were 3.4, 3.8 and 3.8 with 18 degrees of freedom. Corresponding p-values were of the order of 0.000 which are small (less than 0.05 ), this shows back massage improved letdown reflex significantly in experimental group than control group.

\section{Discussion}

Total 20 mothers were assessed using Non probability purposive sampling technique.pre assessment of let down reflex based on semi structured questionnaire and observation check list was done. Back massage was given 4 times in a day for 3 days and assessed let down reflex. The study concluded that there was a significant increase in the let down score in experimental group than control group. The results of this study cannot be generalized to all mothers who had undergone cesarean section, as the size of sample in this study was small. It was very difficult to isolate the back massage from those of other sources like mass media, friends, Internet, magazine etc.

\section{Conclusion}

In the Indian context, there are many studies carried out on the breast feeding but no studies are carried out to enhance the lactation by non invasive, in expensive , Independent nursing practice Lactation improved significantly after back massage in experimental Group.

\section{Scope of the Study}

Finding suggests that, maternal stress during labor and delivery, age, coping with new role were associated with delayed breast fullness, less milk volume and poor let down reflex. The study attempted an independent intervention for mothers to improve lactation.

\section{Acknowledgement}

The Author is thankful to administrative authority of Bharati Vidyapeeth college of Nursing and Bharati Hospital for their cooperation.

\section{References}

[1] Tiwari R, Mahajan PC, Lahariya C. The determinants of exclusive breast feeding in urban slums: a community based study. Journal of Tropical Pediatrics. 2008:1-6. [PubMed]

[2] Khan ME. Breast-feeding and weaning practices in India. Asia-Pacific Population Journal. 2001;5:71-88. [PubMed]

[3] Riordan JM, Gill-Hopple K, Angeron J. Indicators of effective breastfeeding and estimates of breast milk intake. J Hum Lactation . 2005;21:406-412.

[4] WHO. Child and Adolescent Health and Development, Global strategy for infant and young child feeding.2004.

[5] Journal of pediatric health care: official publication of National Association of Pediatric Nurse Associates \& Practitioners (2013) Volume: 27, Issue: 2, Pages: 83-90

\section{Author Profile}

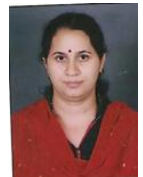

Mrs Bhagyashree Anil Jogdeo, Assistant Professor,Bharati Vidyapeeth College of Nursing Pune, India from 2006,Completed MSc. In 2010 and had 14 years of clinical experience. Presently registered as Ph.D. Nursing in Bharati Vidyapeeth, Pune India in 2012. 